\title{
Metabolism of Arterial Plasma Estrogens by the Splanchnic Organs of the Dog In Vivo
}

\author{
Delwood C. Collins, Hugh D. Robinson, Carolyn M. Howard, and \\ JoHN R. K. PREEdY
}

From the Division of Endocrinology, Department of Medicine, Emory

University, Atlanta, Georgia 30322

A B S T R A C T In order to study the splanchnic metabolism of blood-borne estrogens, a constant infusion of estrone- $6,7-{ }^{8} \mathrm{H}$ was made in a series of dogs, and arteriovenous ( $\mathrm{A}-\mathrm{V})$ differences at equilibrium were determined for estrone- $6,7-{ }^{3} \mathrm{H}$ and for its products estradiol$17 \beta$, estrone sulfate, estrone glucosiduronate, and estradiol-17 $\beta$ glucosiduronate across the splanchnic bed (artery-hepatic vein), the small intestine (artery-superior mesenteric vein), and the spleen (artery-splenic vein). Per cent extractions $(100-[\mathrm{V} / \mathrm{A}] 100)$ were calculated. The plasma metabolic clearance rate (MCR) for estrone was measured. Principal findings were as follows: mean MCR was 731 liters/day per $\mathrm{m}^{2}$, sEM 50 . By comparison with estimated hepatic plasma flow and using the observed splanchnic extraction of estrone, $45-71 \%$ of estrone metabolism was calculated to be extrasplanchnic. The significant mean per cent extractions were as follows (SEM in parentheses): splanchnic bedestrone 85.9 (1.92), estradiol-17 $\beta$ 88.11 (3.36), estrone sulfate 27.9 (5.22), estrone glucosiduronate - 48.5 (9.33), estradiol-17 $\beta$ glucosiduronate -33.3 (8.03) ; small intestine-estrone 45.3 (2.60), estradiol$17 \beta 46.1$ (12.9), estrone glucosiduronate - 30.8 (7.9); spleen-estrone 35 (3.8), estrone glucosiduronate 12 (3.7). These results lead to the following conclusions. Both estrone and estradiol-17 $\beta$ are nearly completely extracted in one passage through the splanchnic bed. There is net uptake of estrone sulfate and net production of estrone glucosiduronate and of estradiol-17 $\beta$ glucosiduronate by the splanchnic bed. There is net uptake of estrone and of estradiol-17 $\beta$ by the intestine, associated with substantial net production of estrone glucosiduronate. There is net uptake of estrone by the spleen and a small but significant net uptake of estrone glucosiduronate.

Received for publication 28 April 1970 and in revised form 2 Jun 1970.

\section{INTRODUCTION}

The evident importance of the enterohepatic circulation of estrogens in the human has stimulated considerable investigation into the details of its operation. Thus, a number of studies have been devoted to the nature and origin of estrogen secreted into the bile (1-12). Furthermore, it has recently been shown that estrogens are actively metabolized as they pass through the enterohepatic circulation. For instance, estrogens brought to the intestine via the bile undergo transformations in the intestinal lumen and on passage through the intestinal wall $(5,6,10-12)$. The transformations have been well documented in the case of estriol conjugates $(6,10-12)$.

However, these studies relate mainly to estrogens within the human enterohepatic circulation. There is virtually no knowledge in any species regarding the immediate metabolism of estrogens brought to the splanchnic area in arterial blood, and the nature and amounts of estrogens released by the splanchnic area into the systemic venous system. We are also largely ignorant of the separate activities of the major splanchnic organs in the metabolism of arterial estrogens and of the nature and relative concentrations of estrogens in the different parts of the splanchnic venous system.

It is therefore clear that an investigation of over-all splanchnic metabolism of arterial estrogens, together with an analysis of the separate activity of intestines and spleen, would be of a great potential value. Appropriate studies in the human have been impeded by the difficulty in approaching the venous sampling sites. An animal model was therefore necessary, and the male dog was chosen. The metabolism of radioactive estrone by this animal was recently investigated in work from this laboratory and found to be similar (within the limits of the investigation) to that in the human, except for the substitution of the product estriol-16 $\alpha, 17 \alpha$ for the human estriol-16 $\alpha, 17 \beta$ (13). Furthermore, this animal is 
known to have an enterohepatic circulation for estrogens (14).

Accordingly, constant infusions of estrone- $6,7-{ }^{8} \mathrm{H}$ were set up in a series of male dogs, and simultaneous arteriovenous concentration differences were determined for radioactive estrone and for its products estradiol-17 $\beta$, estrone sulfate, estrone glucosiduronate, and estradiol$17 \beta$ glucosiduronate across the splanchnic bed as a whole (artery-hepatic vein), across the intestine (artery-superior mesenteric vein), and across the spleen (arterysplenic vein). In order to relate splanchnic estrone metabolism to over-all estrone metabolism, estrone metabolic clearance rates (MCR) were also estimated.

\section{METHODS}

Operative procedure. Mongrel male dogs weighing 14.5$29.9 \mathrm{~kg}$ were anaesthetised with i.v. pentobarbital, $25 \mathrm{mg} / \mathrm{kg}$. An intratracheal tube was inserted. A cardiac catheter was passed into the right jugular vein and thence into the hepatic vein under fluoroscopic control. The catheter was passed as far into the liver substance as possible. The position of the catheter tip was checked at intervals by fluoroscopy. The right lobe of the liver was catheterized usually, and the left lobe occasionally. No difference in results relative to the lobe catheterized was observed. A1though no studies to determine specifically the effect of pentobarbital anesthesia on splanchnic estrogen metabolism were carried out, the widespread use of this anaesthetic in studies in the dog and its absence of effects on hepatic blood flow (15) and oxygen consumption (16) seemed to justify its use in these experiments without further testing.

A small incision was made in the abdominal wall. A small plastic catheter was inserted into a branch of the superior mesenteric vein draining the small intestine and secured, the tip pointing towards the intestine. A small plastic catheter was also inserted into the splenic vein and secured with its point as near the spleen substance as possible (to avoid reflux from the left gastroepiploic vein). The abdomen was closed leaving the sampling ends of the catheters outside. All three veins (hepatic vein, superior mesenteric vein, and splenic vein) were not necessarily catheterized in the same dog. The femoral artery was catheterized. The left jugular vein was catheterized for introducing the loading dose and infusion. Blood samples $(5 \mathrm{ml})$ were drawn simultaneously from each sampling site into heparinized tubes. Total volume of blood withdrawn was usually $45 \mathrm{ml}$, or occasionally 60 $\mathrm{ml}$, over a $15-20 \mathrm{~min}$ period. No effects due to the withdrawal of this relatively small volume of blood were observed.

Loading dose and infusion of estrone- $6,7-^{3} \mathrm{H}$. Authentic estrone-6,7- ${ }^{3} \mathrm{H}$ (see below) was dissolved in $0.1 \mathrm{ml}$ of $95 \%$ ethanol, and diluted to $20-30 \mathrm{ml}$ with $0.9 \%(\mathrm{w} / \mathrm{v})$ saline. The loading dose (radioactivity approximately $20 \mu \mathrm{Ci}$, mass approximately $0.15 \mathrm{ng}$ ) was given into the left jugular vein as a single injection. The infusion (radioactivity approximately $100 \mu \mathrm{Ci}$, mass approximately $0.75 \mathrm{ng}$ ) was drawn into a calibrated syringe, which was then inserted into a Harvard constant infusion pump (Harvard Apparatus Co., Inc., Millis, Mass.), connected to the left jugular vein catheter, and administered at a constant rate immediately after the loading dose. Aliquots of loading dose and of infusion were taken for subsequent radioactivity measurement. The whole infusion was administered in $35-45 \mathrm{~min}$. After 20 min of infusion, samples were obtained from catheterized sites as described above at approximately 5 -min intervals.

Estrogen standards. Estrone-6,7-3 $\mathrm{H}$ (stated specific activity $30-50 \mathrm{Ci} / \mathrm{mmole}$ ) was obtained from New England Nuclear Corp. (Boston, Mass.). Each batch, which was used within 2 months of receipt, was tested at intervals for radiochemical purity using column partition chromatography as already described (17). Over $96 \%$ of the total radioactivity was contained in a chromatographic peak which corresponded exactly to a peak due to authentic nonradioactive estrone (see below) when both radioactive and nonradioactive substances were chromatographed together. On crystallization of a mixture of the radioactive material and authentic nonradioactive estrone, specific activity of crystals and mother liquor corresponded and did not vary significantly on repeated crystallization. Estradiol$17 \beta-6,7-{ }^{3} \mathrm{H}$ (stated specific activity $30-50 \mathrm{Ci} / \mathrm{mmole}$ ) and estrone-6,7-8 $\mathrm{H}$ sulfate (stated specific activity $10-15 \mathrm{Ci} /$ mmole) were obtained from New England Nuclear Corp. These substances were used only in recovery experiments. Tests for radiochemical purity were carried out as described above for estrone with similar results. Authentic estrone, estradiol-17 $\beta$ and estrone sulfate standards were obtained from Mann Research Labs. Inc., New York. In each case melting points were in the expected range. On column partition chromatography approximately $95 \%$ of the total fluorescence (see below) of each standard was contained in a single peak in the chromatographic position expected for each substance. Nonradioactive estrone glucosiduronate and estradiol-17 $\beta$-17-glucosiduronate standards were very kindly given by Dr. A. E. Kellie. The methods of synthesis of these conjugates have been described (18). On testing $>95 \%$ of total fluorescence was contained in a single peak after column partition chromatography. Estradiol-17 $\beta$-3-glucosiduronate was prepared by sodium borohydride reduction of estrone glucosiduronate.

Fluorometry. Fluorescence was obtained by heating the estrogens with sulfuric acid and was measured as described by Preedy and Aitken (19).

Radioactivity measurements. Radioactivity was measured by scintillation counting, using a Packard (Model 3000 or 4000 series) scintillation spectrometer (Packard Instrument Co., Downers Grove, I11.). For estrone, estradiol-17 $\beta$, and estriol, the conditions (including scintillation fluid) were those previously described (13). The estrogen conjugates were counted in $0.2 \mathrm{ml}$ of water mixed with $10 \mathrm{ml}$ of dioxane containing $10 \mathrm{~g} /$ liter of 2,5-diphenyloxazole, 0.15 $\mathrm{g} /$ liter of 1,4-bis-2(4-methyl-5-phenyloxazole)-benzene, 150 $\mathrm{g} /$ liter of naphtalene, and $20 \mathrm{ml} / \mathrm{liter}$ of ethylene glycol.

Determination of estrogens in plasma samples. Plasma was separated promptly from red cells and stored at $-15^{\circ} \mathrm{C}$ until analyzed. Known amounts of estrone, estradiol-17 $\beta$, estrone sulfate, estrone glucosiduronate, and estradiol-17 $\beta$ 17-glucosiduronate were added as internal standards to $8 \mathrm{ml}$ of $95 \%$ aqueous ethanol. An aliquot (usually $1 \mathrm{ml}$ ) of plasma was then added drop-wise to the aqueous ethanol with stirring to precipitate proteins. The precipitate was separated by filtration or centrifugation, then the filtrate or supernatant was dried. The dried extract was redissolved in $70 \%$ aqueous methanol and kept at $-15^{\circ} \mathrm{C}$ for $48 \mathrm{hr}$ to precipitate lipids. The precipitate was separated by centrifugation or filtration at $-15^{\circ} \mathrm{C}$, and the supernatant or filtrate was dried.

Unconjugated estrone and unconjugated estradiol-17 $\beta$. The dried extract was partitioned between ether and water. The aqueous phase was saved. The ether extract was dried, 
redissolved in a small amount of stationary phase, and applied to the column partition system of Preedy and Aitken (19). Chromatography was carried out as described (19) except that only the first two sequential mobile phases were used $(13,19)$, to separate estrone and estradiol-17 $\beta$. Fractions were collected and were analyzed for radioactivity and for the mass of the internal standards, estrone and estradiol-17 $\beta$.

Estrone sulfate. The aqueous phase previously saved was adjusted to $\mathrm{pH} 6.0$ using $0.1 \mathrm{~m}$ acetate buffer and $2 \mathrm{mg}$ of the phenolsulphatase preparation Mylase $P$ (Wallerstein Laboratories) per $\mathrm{ml}$ of solution added. The solution was incubated at $37^{\circ} \mathrm{C}$ for $18 \mathrm{hr}$. The aqueous phase was then extracted with ether as described above. The aqueous phase was saved. The ether fraction was evaporated and the residue chromatographed as already described for unconjugated estrone and estradiol-17 $\beta$. Fractions were collected and analyzed for radioactivity and for the mass of estrone (derived from added estrone sulfate) as described above. (No estradiol-17 $\beta$ sulfate was found in any sample.)

Estrone glucosiduronate and estradiol-17 $\beta$ glucosiduronate. The aqueous phase previously saved was adjusted to $\mathrm{pH} 5.0$ using $0.1 \mathrm{M}$ acetate buffer. Beef liver $\beta$-glucuronidase (Ketodase, Warner-Chilcott Laboratories, Morris Plains, N. J.) was added $(100,000 \beta$-glucuronidase $U / 100 \mathrm{ml}$ of solution) and incubated for $16 \mathrm{hr}$ at $37^{\circ} \mathrm{C}$. The solution was then extracted with ether, and the ether extract was subjected to column partition chromatography as described above. Fractions were collected, and radioactivity and mass of the added standards were measured (as the aglycones), as described above. This procedure measures estrone glucosiduronate and estradiol-17 $\beta$ glucosiduronate (the term estradiol-17 $\beta$ glucosiduronate is here used to mean any glucosiduronate or mixture of glucosiduronates of estradiol-17 $\beta$ ).

Correction for methodological losses. Values obtained for the concentration of radioactive estrogens were corrected for losses by means of the internal standards in the normal way. Recoveries of the internal standards were in the following range: estrone and estradiol- $17 \beta, 75-85 \%$; estrone sulfate, $60-75 \%$; and estrone and estradiol-17 $\beta-17$-glucosiduronate, $50-70 \%$.

In later experiments estradiol-17 $\beta$-17-glucosiduronate was used as the only glucosiduronate internal standard, since the amounts of estrone glucosiduronate available were limited. However, it had previously been shown that recovery of estrone glucosiduronate and of estradiol-17 $\beta$-17-glucosiduronate standards were similar, so that this imposed restriction did not alter the analytical conditions significantly.

In the last few experiments (dogs 19, 20, and 21) no standards were added. In the previous experiments the rate of recovery of each of the standards used has been established. Consequently, it was considered justifiable to use the observed mean recovery rate to correct for losses in those dogs where this was necessary (as in the MCR determinations, Table I). For the A-V differences this correction was not applied, since recovery rates from arterial and venous samples would be similar.

Test of the extraction procedure. Known amounts of the internal standards, estrone (about $10 \mu \mathrm{g}$ ), estradiol-17 $\beta$ (about $10 \mu \mathrm{g}$ ), estrone sulfate (about $10 \mu \mathrm{g}$ ), estrone glucosiduronate (about $30 \mu \mathrm{g}$ ), and estradiol-17 $\beta$-17-glucosiduronate (about $30 \mu \mathrm{g}$ ), were added separately and in turn to the plasma ethanol mixture described above using $1 \mathrm{ml}$ of plasma from untreated dogs. The analytic procedure was then continued. When either estrone or estradiol-17 $\beta$ were added, virtually all added material was recovered in the first ether extract, as demonstrated after partition chromatography and sulfuric acid fluorescence. None of the added estrone or estradiol-17 $\beta$ could subsequently be detected after Mylase $\mathrm{P}$ and Ketodase treatments with ether extraction, partition chromatography, and fluorometry after each treatment. On estrone sulfate addition, no estrone or estradiol-17 $\beta$ was detected in the first ether extract or third ether extract after Ketodase. After Mylase P most of the estrone sulfate was recovered as estrone in the second ether extract. When estrone glucosiduronate or estradiol-17 $\beta$-17-glucosiduronate were added, no estrone or estradiol-17 $\beta$ was detected either in the first ether extract or in the second ether extract after Mylase $P$ treatment. Most of the estrone glucosiduronate and estradiol-17 $\beta$-17-glucosiduronate was recovered after the Ketodase treatment and the third ether extraction.

Identification of radioactize unconjugated estrogens. Further identification of the radioactivity peaks presumed due to estrone and estradiol-17 $\beta$ both in the unhydrolyzed and the hydrolyzed plasma samples was obtained in the following two ways: $(a)$ demonstration that the specific activity of a mixture of the material forming a radioactive peak with the corresponding nonradioactive estrogen standard did not change significantly after acetylation and rechromatography carried out as already described (13), and $(b)$ demonstration that on crystallization of a mixture of the material forming a radioactive peak and the corresponding nonradioactive estrogen standard the specific activity of crystals and mother liquor were similar and did not change significantly after repeated crystallization (13).

Identification of radioactive conjugated estrogens. More direct identification of the radioactive conjugates (estrone sulfate, estrone glucosiduronate, and estradiol-17 $\beta$ glucosiduronate) were carried out as follows. Plasma from artery and from hepatic, superior mesenteric and splenic veins (one sample from each site) was extracted with ether, and the ether fraction discarded. The aqueous phase was made $80 \%$ in respect of ethanol and was centrifuged. The following nonradioactive standards were added to the supernatant: estrone sulfate, estrone glucosiduronate, estradiol-17 $\beta$-3-glucosiduronate, and estradiol-17 $\beta$-17-glucosiduronate. The dried extract was applied to a Florisil column and eluted successively with $50 \mathrm{ml}$ each of ethyl acetate, ethyl acetate-methanol $(1: 1)$, methanol, and methanol-water $(1: 1)$. In this system estrogen sulfates are eluted in the ethyl acetate-methanol mixture and glucosiduronates in the methanol and methanol-water mixtures.

The ethyl acetate-methanol fraction (sulfates) was dried down, a further estrone sulfate standard was added, and the material was rechromatographed on a celite column using chloroform : $n$-heptane: $t$-butanol : $1 \mathrm{M} \mathrm{NH}_{4} \mathrm{OH}$ (150:75:25: 300 ). Aliquots of the fractions containing estrone sulfate were analyzed for radioactivity and mass as already described. The remainder of the material was chromatographed again on Silica Gel G plates with benzene: methyl ethyl ketone: ethanol: water $(3: 3: 3: 1)(20)$ as eluent, with standard estrone sulfate as marker. Radioactivity and mass were again determined. Specific activity of the material did not change significantly after the two chromatographic procedures. An aliquot was treated with Mylase $\mathrm{P}$ under conditions already described, and the hydrolysis product identified as estrone, using chromatography, derivative formation, and repeated crystallization as already described.

Material eluted in the methanol and methanol-water fractions (glucosiduronates) from the Florisil column was combined with additional estrone glucosiduronate, estradiol$17 \beta$-3-glucosiduronate, and estradiol-17 $\beta$-17-glucosiduronate 
standards and chromatographed with DEAE-Sephadex, using as eluent increasing concentrations of $\mathrm{NaCl}(0.1-0.2$ mole/liter) in water in the form of a linear gradient (21). This system separates estrone and estradiol-17 $\beta$ glucosiduronates. The specific activity of material forming the estrone glucosiduronate peak was estimated. The material was then subjected to thin-layer chromatography on Silica Gel $G$ plates with benzene: methanol:acetic acid (70:30: 10) and instant thin-layer chromatography (ITLC) (silica gel impregnated glass fiber sheets, Gelman Instrument Company, Ann Arbor, Mich.) with chloroform: acetone: acetic acid mixtures $(75: 25: 5$ or $75: 50: 5)$ as eluent. Specific activities of the material corresponding to estrone glucosiduronate were again determined and did not change significantly after chromatography. The material was then hydrolyzed using Ketodase (as already described), and the hydrolysis product identified as estrone by derivative formation and by repeated crystallization as already described.

The estradiol-17 $\beta$ glucosiduronate zone from the DEAESephadex column contained two adjacent radioactivity peaks. The smaller peak corresponded with the added estradiol-17 $\beta$ 17-glucosiduronate standard. The specific activity of this peak was estimated, and the material rechromatographed in the thin-layer systems described above. Specific activity of the material corresponding to estradiol-17 $\beta$-17-glucosiduronate was determined and was found not to change significantly after chromatography. The larger estradiol-17 $\beta$ glucosiduronate peak corresponded with the estradiol-17 $\beta$ 3 -glucosiduronate standard. The material contained in each estradiol-17 $\beta$ glucosiduronate peak was hydrolyzed separately using Ketodase. The product of hydrolysis in each case was identified as estradiol-17 $\beta$ by derivative formation and repeated crystallization as already described. Details of the above procedures for identifying estrogen conjugates will be described elsewhere.

Calculation of metabolic clearance rate (MCR) and pcr cent extraction (\% extr.). The MCR of estrone was calculated in the usual way (22) using the formula MCR = $r / x_{1}$, where $r$ is the rate of radioactive estrone infusion $(\mathrm{cpm} / \mathrm{min})$, and $\mathrm{x}_{1}$ the concentration of arterial radioactive estrone at equilibrium $(\mathrm{cpm} / \mathrm{ml})$. This gives the MCR in $\mathrm{ml} /$ min, which can then be converted to $\mathrm{ml} / \mathrm{min}$ per $\mathrm{kg}$, or liter/ day per $\mathrm{m}^{2}$ (Table $\left.\mathrm{I}\right)$. The surface area of the $\operatorname{dog}\left(\mathrm{m}^{2}\right)$ was calculated from the weight of the dog by the Meeh-Rubner formula (23). The per cent extraction $=100-[\mathrm{V} / \mathrm{A}] 100$, where $\mathrm{V}$ is the concentration $(\mathrm{cpm} / \mathrm{ml})$ of a radioactive estrogen in a vein and $A$ the concentration $(\mathrm{cpm} / \mathrm{ml})$ of the same radioactive estrogen in an artery, when samples are obtained simultaneously.

Statistics. The statistical design consisted of the following two complementary analyses: $(a)$ analysis for regression and $(b)$ analysis for random variation or scatter. To determine the significance of trends related to time, linear regression analysis was carried out on the serial arterial and venous concentrations in each dog, where a series contained more than two observations. The series of per cent extractions in each dog were similarly analyzed. For the analysis for random variation, means $(m)$, standard error of the mean (SEM), and coefficients of variation ( $C$ of $V=S E M ~ X$ $100 / \mathrm{m}$ ) were calculated by standard procedures. For the $\mathrm{A}-\mathrm{V}$ differences the mean difference (d) and standard error of the mean difference ( SEM $_{d}$ ) were calculated by the usual methods, and the paired $t$ test used to test the significance of a mean difference. The significance of a mean per cent extraction was estimated by testing the significance of the difference between the mean per cent extraction and zero. A value for $P$ of $<0.03$ is taken to indicate "significance." The importance of each form of statistical analysis in the interpretation of the data is brought out in the Discussion section.

\section{RESULTS}

Significant regression was found in a small percentage of series only, as follows: 2 (artery, dog 18; superior mesenteric vein, $\operatorname{dog} 5$ ) of 38 series of estrone values, 2 (hepatic vein, dog 19; superior mesenteric vein, dog 10) in 23 series of estrone sulfate values, and 8 in 35 series of estrone glucosiduronate values (artery, dogs 12, 18, 21,25 ; hepatic vein, $\operatorname{dogs} 6,12$; superior mesenteric vein, dogs 6,18$)$. There was no significant regression in any of the series of estradiol-17 $\beta$ or estradiol-17 $\beta$ glucosiduronate values. There were therefore only 12 instances of significant regression in a total of 138 arterial and venous series. Analysis of the per cent extractions showed that significant regression was present only for estrone glucosiduronate, 3 of 24 series (artery-hepatic vein, $\operatorname{dogs} 8,18$; artery-superior mesenteric vein, $\operatorname{dog}$ 22). There were therefore only three instances of significant regression in a total of 81 series of per cent extractions. Where regression was observed the values for the regression coefficient were positive (indicating rising values with time), except in two of the three per cent extraction series for estrone glucosiduronate, where the values were negative (dogs 18,22).

The plasma metabolic clearance rate (MCR) for estrone in 11 dogs is given in Table I. MCR's are expressed as $\mathrm{ml} / \mathrm{min}, \mathrm{ml} / \mathrm{min}$ per $\mathrm{kg}$, and liter/day per $\mathrm{m}^{2}$ for internal comparison and for comparison with published results from the human. Mean MCR as $\mathrm{ml} / \mathrm{min}$ was 931 (SEM 76), as $\mathrm{ml} / \mathrm{min}$ per $\mathrm{kg}$ was 42.2 (SEM 2.9) and as liter/day per $\mathrm{m}^{2}$ was 731 (SEM 50). Coefficients of variation were $8.1,6.9$, and 6.8 , respectively, indicating a decrease in scatter when correction for weight was applied. There was little further decrease when the figures were corrected for estimated surface area. The series from which the average arterial estrone values (Table I, column 3) were calculated are given in Table IV. There was no significant regression in any of these series.

The values for estrone, estradiol-17 $\beta$, estrone sulfate, estrone glucosiduronate, and estradiol-17 $\beta$ glucosiduronate in artery (A) and hepatic vein (HV) plasma sampled simultaneously are given in Table II, together with the per cent extractions. There was a significant mean A-HV difference ( 12 dogs, 39 samples) for estrone $(P<0.001)$ and a mean per cent extraction of 85.9 (SEM 1.92), which was significantly different from zero $(P<0.001)$. The results for estradiol-17 $\beta$ (11 dogs, 26 samples) were similar. There was a significant mean A-HV difference $(P<0.001)$ and a mean per cent extraction of 88.1 (SEM 3.36), which was significantly different from zero $(P<0.001)$. 
TABLE I

Plasma Metabolic Clearance Rate of Estrone in 11 Dogs

\begin{tabular}{|c|c|c|c|c|c|}
\hline \multirow{3}{*}{ Dog } & \multicolumn{2}{|c|}{ Estrone-6, 7-8H } & \multirow{2}{*}{\multicolumn{3}{|c|}{ Plasma metabolic clearance rate }} \\
\hline & \multirow{2}{*}{$\begin{array}{c}\begin{array}{c}\text { Infusion } \\
\text { rate }\end{array} \\
c p m / \min \times 10^{3}\end{array}$} & \multirow{2}{*}{$\begin{array}{c}\begin{array}{c}\text { Average* } \\
\text { arterial } \\
\text { plasma }\end{array} \\
\text { concentration }\end{array}$} & & & \\
\hline & & & $\mathrm{ml} / \mathrm{min}$ & $\mathrm{ml} / \mathrm{min}$ per $\mathrm{kg}$ & liter/day per $m^{2}$ \\
\hline 6 & 2190 & 1920 & 1140 & 57.0 & 959 \\
\hline 7 & 1920 & 2190 & 877 & 51.0 & 817 \\
\hline 8 & 1930 & 2380 & 810 & 32.8 & 592 \\
\hline 9 & 2310 & 1730 & 1330 & 44.6 & 857 \\
\hline 10 & 2270 & 3070 & 738 & 29.1 & 530 \\
\hline 12 & 2400 & 5000 & 481 & 33.2 & 502 \\
\hline 15 & 2080 & 1730 & 1200 & 55.2 & 953 \\
\hline 17 & 1860 & 2330 & 800 & 33.3 & 596 \\
\hline 19 & 3020 & 2660 & 1140 & 44.0 & 801 \\
\hline 20 & 1350 & $1810 \ddagger$ & 744 & 38.2 & 636 \\
\hline \multirow[t]{4}{*}{21} & 1310 & $1320 \ddagger$ & 991 & 46.5 & 799 \\
\hline & & Mean & 931 & 42.2 & 731 \\
\hline & & SEM & 76 & 2.9 & 50 \\
\hline & & $\begin{array}{l}\text { Coefficient } \\
\text { of variation }\end{array}$ & 8.1 & 6.9 & 6.8 \\
\hline
\end{tabular}

* Average of three or four consecutive samples obtained at approximately 5-min intervals.

$\ddagger$ Values corrected for average recovery rate of $80 \%$ (see text).

There was a significant mean A-HV difference (10 dogs, 28 samples $)$ for estrone sulfate $(P<0.001)$ and a mean per cent extraction of 27.9 (SEM 5.22), which was significantly different from zero $(P<0.001)$.

There was a significant mean A-HV differences (13 dogs, 41 samples) for estrone glucosiduronate $(P<$ 0.001 ), but in this case the mean difference was negative. The mean per cent extraction was - 48.5 (SEM 9.33) which was significantly different from zero $(P<0.001)$. Exclusion of the two cases in which there was significant regression in the series of per cent extractions (dogs 8 , 18) had no significant effect on these statistics.

The findings for estradiol-17 $\beta$ glucosiduronate were similar to those for estrone glucosiduronate. There was a significant mean A-HV difference (11 dogs, 27 samples) $(P<0.01)$, and this was negative. The mean per cent extraction was -33.3 (SEM 8.03) and was significantly different from zero $(P<0.001)$.

Corresponding values for artery (A) and superior mesenteric vein (SMV) plasma are given in Table III. There was a significant mean A-SMV difference ( 9 dogs, 29 samples $)$ for estrone $(P<0.005)$ and a mean per cent extraction of 45.3 (SEM 2.60), significantly different from zero $(P<0.001)$. Similar results were obtained for estradiol-17 $\beta$. The mean A-SMV difference ( 5 dogs, 12 samples) was significant $(P<0.01)$ as was the mean per cent extraction of 46.1 (SEM 12.9) $(P<0.003)$.
There was no significant A-SMV difference for estrone sulfate ( 7 dogs, 17 samples) or for estradiol-17 $\beta$ glucosiduronate ( 5 dogs, 13 samples) and no significant mean extraction. However, the comparatively high values for SEMd and SEM should be noted.

There was a significant mean A-SMV difference (8 dogs, 25 samples) for estrone glucosiduronate $(P<$ 0.02 ), and this was negative. The mean per cent extraction was likewise significant and was negative, -30.8 (SEM 7.9) $(P<0.003)$. Exclusion of the single case in which significant regression in the per cent extraction series occurred ( $\operatorname{dog} 22)$ did not significantly affect the statistical results.

The mean A-SMV difference and mean per cent extraction for estradiol-17 $\beta$ was not significant ( 5 dogs, 13 samples). Here again the relatively high values for SEMd and SEM should be noted.

Values for arterial (A) and splenic vein (SPV) concentrations of estrone and estrone glucosiduronate are given in Table IV. (Values for estradiol-17 $\beta$, estrone sulfate, and estradiol-17 $\beta$ glucosiduronate are omitted since many concentrations were too low to be estimated accurately, and the remaining figures were too few to allow meaningful statistical analysis.) There was a significant mean A-SPV difference (5 dogs, 15 samples) for estrone $(P<0.01)$ and a significant mean per cent extraction of 35 (SEM 3.8) $(P<0.01)$. There was a 
TABLE II

Simultaneous Arterial $(A)$ and Hepatic Venous (HV) Plasma Concentrations and Per Cent Extraction (\% extr.) of Radioactive

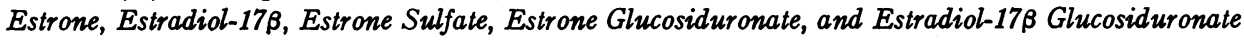
after Infusion of Estrone-6,7-3 $\mathrm{H}$ in 14 Dogs

\begin{tabular}{|c|c|c|c|c|c|c|c|c|c|c|c|c|c|c|c|c|}
\hline \multirow[b]{2}{*}{$\begin{array}{l}\text { Dog } \\
\text { No. }\end{array}$} & \multirow[b]{2}{*}{$\begin{array}{l}\text { Sample } \\
\text { No. }\end{array}$} & \multicolumn{3}{|c|}{ Estrone } & \multicolumn{3}{|c|}{ Estradiol-17\% } & \multicolumn{3}{|c|}{ Estrone sulfate } & \multicolumn{3}{|c|}{ Estrone glucosiduronate } & \multicolumn{3}{|c|}{$\begin{array}{c}\text { Estradiol-17 } \beta \\
\text { glucosiduronate }\end{array}$} \\
\hline & & $\mathbf{A}$ & HV & $\begin{array}{c}\% \\
\text { extr.* }\end{array}$ & A & $\mathrm{HV}$ & $\begin{array}{c}\% \\
\text { extr.* }\end{array}$ & A & HV & $\begin{array}{c}\% \\
\text { extr.* }\end{array}$ & A & HV & $\begin{array}{c}\% \\
\text { extr.* }\end{array}$ & A & HV & $\begin{array}{c}\% \\
\text { extr.* }\end{array}$ \\
\hline & & \multicolumn{2}{|c|}{$c p m / m l$} & & \multicolumn{2}{|c|}{$c p m / m l$} & & \multicolumn{2}{|c|}{$c p m / m l$} & & \multicolumn{2}{|c|}{$c p m / m l$} & \multicolumn{4}{|c|}{$c p m / m l$} \\
\hline \multirow[t]{3}{*}{5} & 1 & 8680 & 630 & 93 & & & & & & & 10800 & 16000 & -54 & 1400 & 1950 & -39 \\
\hline & 2 & 10500 & 443 & 96 & 544 & 73 & 87 & & & & 31000 & 35700 & -15 & 4510 & 5380 & -22 \\
\hline & 3 & 12900 & 517 & 96 & 915 & 134 & 85 & & & & 25300 & 30100 & -19 & 4000 & 4890 & -22 \\
\hline \multirow[t]{4}{*}{6} & 1 & 1970 & 245 & 88 & & & & & & & 713 & 1110 & -56 & & & \\
\hline & 2 & 1630 & 100 & 94 & & & & & & & 1280 & 2010 & -57 & & & \\
\hline & 3 & 2060 & 77 & 96 & 219 & 0 & 100 & & & & 2320 & 3230 & -39 & 1080 & 858 & 21 \\
\hline & 4 & 2020 & 125 & 94 & 120 & 67 & 44 & 296 & 215 & 27 & 4940 & 4900 & 1 & 814 & 793 & 3 \\
\hline 7 & 1 & 2100 & 190 & 91 & 299 & 0 & 100 & 239 & 147 & 38 & 845 & 1200 & -42 & 406 & 348 & 14 \\
\hline & 2 & 1872 & 122 & 94 & 316 & 0 & 100 & 208 & 144 & 31 & 501 & 1361 & -171 & 440 & 449 & -2 \\
\hline & 3 & 2600 & 144 & 95 & 384 & $\mathbf{0}$ & 100 & 306 & 261 & 15 & 1390 & 2040 & -47 & 392 & 391 & $\mathbf{0}$ \\
\hline 8 & 1 & 2410 & 375 & 84 & 253 & 0 & 100 & 149 & 179 & -20 & 2410 & 3450 & -43 & 580 & 960 & -65 \\
\hline & 2 & 1740 & 385 & 78 & 190 & 0 & 100 & 316 & 223 & 29 & 1820 & 2820 & -55 & 499 & 550 & -10 \\
\hline & 3 & 2990 & 425 & 86 & 178 & 0 & 100 & 233 & 325 & -39 & 3180 & 5310 & -67 & 983 & 1400 & -42 \\
\hline 9 & 1 & 1699 & 568 & 67 & 462 & 105 & 77 & 192 & 118 & 39 & 657 & 1110 & -69 & & & \\
\hline & 2 & 1796 & 512 & 72 & 440 & 86 & 81 & 374 & 303 & 19 & 617 & 1100 & -78 & 236 & 385 & -63 \\
\hline & 3 & 1702 & 273 & 84 & 459 & 80 & 83 & 444 & 121 & 73 & 668 & 1150 & -72 & 328 & 708 & -116 \\
\hline 10 & 1 & 3250 & & & 713 & $\mathbf{0}$ & 100 & 403 & 288 & 29 & 2100 & 1900 & 10 & 455 & 610 & -34 \\
\hline & 2 & 2950 & & & 866 & 160 & 82 & 617 & 431 & 30 & 1804 & 3100 & -72 & 717 & 927 & -29 \\
\hline & 3 & 3000 & & & 1200 & 0 & 100 & 626 & 423 & 30 & 2230 & 3180 & -43 & 801 & 1070 & -34 \\
\hline 12 & 1 & 4190 & 231 & 95 & 615 & 65 & 89 & 337 & 75 & 78 & 450 & 754 & -68 & 274 & 200 & 27 \\
\hline & 2 & 3450 & 1180 & 66 & 254 & 167 & 34 & 474 & 259 & 45 & 932 & 3150 & -238 & 570 & 731 & -28 \\
\hline & 3 & 5540 & 455 & 92 & & & & 439 & 204 & 54 & 2030 & 3250 & -60 & & & \\
\hline & 4 & 6803 & 1822 & 73 & & & & 581 & 250 & 57 & 2580 & 5270 & -104 & 805 & 1760 & -118 \\
\hline 15 & 1 & 1900 & & & 175 & & & 205 & & & 948 & & & & & \\
\hline & 2 & 1880 & & & 186 & & & 160 & & & 1210 & & & 331 & & \\
\hline & 3 & 1410 & & & 224 & & & 206 & & & 1620 & & & 463 & & \\
\hline 17 & 1 & 2170 & 79 & 96 & 296 & 0 & 100 & 181 & 222 & -22 & 1370 & 1550 & -13 & 229 & 292 & -28 \\
\hline & 2 & 2070 & 153 & 93 & 305 & 77 & 75 & 284 & 118 & 58 & 741 & 1190 & -60 & 292 & 473 & -62 \\
\hline & 3 & 2740 & 111 & 96 & 433 & 0 & 100 & 248 & 215 & 13 & 956 & 1370 & -43 & 176 & 325 & -85 \\
\hline 18 & 1 & 816 & 36 & 96 & & & & & & & 212 & 384 & -81 & & & \\
\hline & 2 & 974 & 78 & 92 & & & & & & & 484 & 798 & -65 & & & \\
\hline & 3 & 1370 & 97 & 93 & & & & & & & 856 & 1333 & -56 & & & \\
\hline & 4 & 1488 & 98 & 93 & & & & & & & 954 & 1323 & -39 & & & \\
\hline 19 & 1 & 2328 & 772 & 67 & & & & 168 & 103 & 39 & 369 & 1020 & -176 & & & \\
\hline & 2 & 2829 & 752 & 73 & & & & 208 & 189 & 10 & 861 & 631 & 58 & & & \\
\hline & 3 & 2816 & 1120 & 60 & & & & 478 & 290 & 39 & 1124 & 884 & 21 & & & \\
\hline 20 & 1 & 1091 & 68 & 94 & & & & & & & & & & & & \\
\hline & 2 & 1612 & 625 & 61 & & & & 144 & 140 & 3 & 230 & 165 & 28 & & & \\
\hline & 3 & 1645 & 723 & 56 & & & & 184 & 189 & -3 & 202 & 536 & -165 & & & \\
\hline 21 & 1 & 989 & 65 & 93 & & & & & & & 1198 & 1460 & -22 & 188 & 262 & -39 \\
\hline & 2 & 1037 & 41 & 96 & 148 & 0 & 100 & & & & 1386 & 1509 & -9 & 132 & 279 & -111 \\
\hline & 3 & 1144 & 65 & 94 & 223 & 0 & 100 & & & & 1513 & 2085 & -38 & 233 & 370 & -59 \\
\hline 22 & 1 & 1639 & 276 & 83 & 376 & 92 & 76 & 114 & 92 & 19 & 485 & 418 & 14 & & & \\
\hline & 2 & 2238 & 208 & 91 & 415 & 31 & 93 & 140 & 100 & 29 & 613 & 643 & -5 & 162 & 116 & 28 \\
\hline & 3 & 3028 & 239 & 92 & 715 & 112 & 84 & 194 & 75 & 62 & 984 & 760 & 13 & 318 & 280 & 12 \\
\hline Mea & an difference & 25 & & & 38 & & & 9 & & & & & & & & \\
\hline SEM & & & & & & & & & & & & & & & 58 & \\
\hline$P$ & & $<0$ & & & $<0$ & & & & 001 & & & & & & & \\
\hline Mea & an $\%$ extr. & & & 85.9 & & & 88.1 & & & 27.9 & & & -48.5 & & & -33.3 \\
\hline $\begin{array}{l}\text { SEM } \\
P t\end{array}$ & & & & 1.92 & & & 3.36 & & & 5.22 & & & 9.33 & & & 8.03 \\
\hline$P \ddagger$ & & & & $<0.001$ & & & $<0.001$ & & & $<0.001$ & & & $<0.001$ & & & $<0.001$ \\
\hline
\end{tabular}

Serial samples were taken at approximately 5 -min intervals.

$* \%$ extr. $=100-[\mathrm{HV} / \mathrm{A}] 100$.

$\ddagger$ Significance of difference between mean per cent extraction and zero. 
TABLE III

Simultaneous Arterial (A) and Superior Mesenteric Venous (SMV) Plasma Concentrations and Per Cent Extraction (\% extr.)

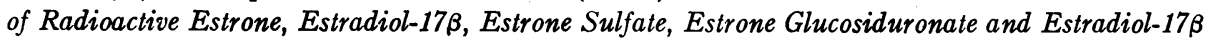
Glucosiduronate after Infusion of Estrone-6,7-3 $\mathrm{H}$ in Nine Dogs

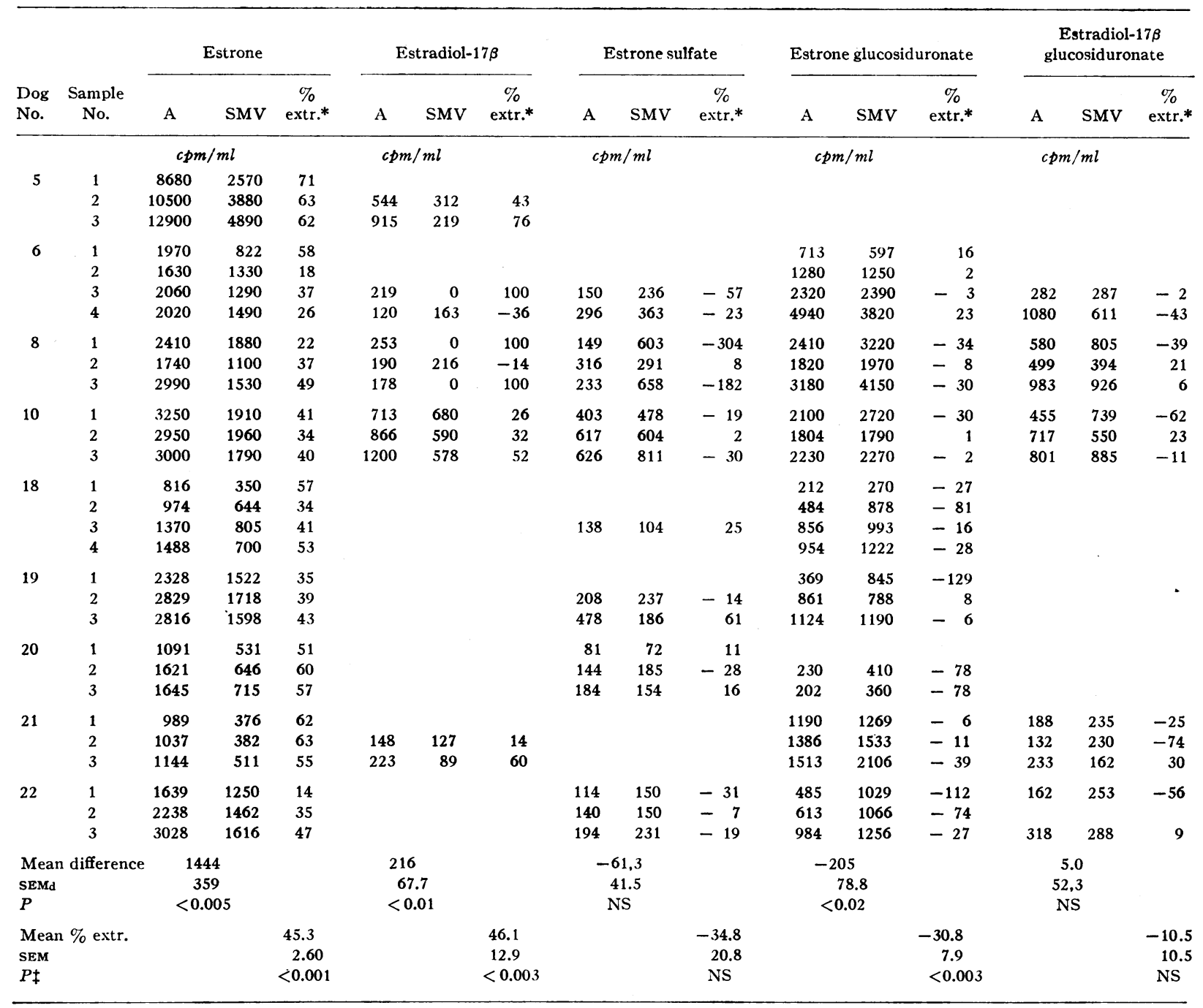

Serial samples were taken at approximately 5-min intervals.

$* \%$ extr. $=100-[\mathrm{SMV} / \mathrm{A}] 100$.

$\ddagger$ Significance of difference between mean per cent extraction and zero.

small but significant mean A-SPV difference (5 dogs, 15 samples) for estrone glucosiduronate $(P<$ 0.01 ) and a mean per cent extraction of 12.0 (SEM 3.7) which was also significant $(P<0.01)$. It is to be noted that the per cent extraction in this instance was positive.

\section{DISCUSSION}

The necessity for establishing a steady state in the determination of the metabolic clearance rate $(\mathrm{MCR})$ is apparent. In particular, there can be no trend with time in the serial arterial concentrations of the infused sub- stance. On regression analysis any value for the regression coefficient significantly different from zero will invalidate the MCR calculation since the concentration at which the system may eventually stabilize is not known. Difficulty has been experienced by some workers in obtaining a steady state both of precursor and of products during the infusion of radioactive estrone and of estradiol-17 $\beta$ in the human (24). In the present work there was no significant linear relationship to time in any of the series of arterial concentrations from which the MCR was calculated (Tables I and II). 
TABLE IV

Simultaneous Arterial $(A)$ and Splenic Venous (SPV) Plasma Concentrations and Per Cent Extraction (\% extr.) of Radioactive Estrone and

Estrone Glucosiduronate after an Infusion of Estrone-6, $7-{ }^{3} \mathrm{H}$ in Five Dogs

\begin{tabular}{|c|c|c|c|c|c|c|c|}
\hline \multirow{2}{*}{$\begin{array}{l}\text { Dog } \\
\text { No. }\end{array}$} & \multirow{2}{*}{$\begin{array}{l}\text { Sample } \\
\text { No. }\end{array}$} & \multicolumn{3}{|c|}{ Estrone } & \multicolumn{3}{|c|}{ Estrone glucosiduronate } \\
\hline & & A & SVP & $\%$ extr.* & A & SVP & $\%$ extr.* \\
\hline & & \multicolumn{3}{|c|}{$c p m / m l$} & \multicolumn{2}{|c|}{$c p m / m l$} & \\
\hline \multirow[t]{3}{*}{21} & 1 & 989 & 771 & 22 & 1198 & 1074 & 11 \\
\hline & 2 & 1037 & 735 & 29 & 1386 & 1248 & 10 \\
\hline & 3 & 1144 & 686 & 40 & 1513 & 1238 & 19 \\
\hline \multirow[t]{3}{*}{22} & 1 & 1639 & 1480 & 10 & 485 & 462 & 5 \\
\hline & 2 & 2238 & 1498 & 33 & 613 & 646 & -5 \\
\hline & 3 & 3028 & 1755 & 42 & 984 & 626 & 36 \\
\hline \multirow[t]{3}{*}{23} & 1 & 995 & 780 & 21 & 372 & 390 & -5 \\
\hline & 2 & 1220 & 776 & 36 & 379 & 414 & -9 \\
\hline & 3 & 1289 & 976 & 24 & 590 & 540 & 8 \\
\hline \multirow[t]{3}{*}{24} & 1 & 214 & 121 & 43 & 216 & 160 & 26 \\
\hline & 2 & 222 & 111 & 50 & 210 & 150 & 29 \\
\hline & 3 & 251 & 122 & 51 & 121 & 110 & 9 \\
\hline \multirow[t]{3}{*}{25} & 1 & 203 & 63 & 69 & 130 & 106 & 18 \\
\hline & 2 & 184 & 125 & 32 & 151 & 156 & -3 \\
\hline & 3 & 200 & 155 & 23 & 179 & 123 & 31 \\
\hline \multicolumn{2}{|c|}{ Mean difference } & \multicolumn{2}{|c|}{313} & & \multicolumn{2}{|c|}{72.3} & \\
\hline \multirow{2}{*}{\multicolumn{2}{|c|}{$\begin{array}{l}\text { SEM }_{\mathbf{d}} \\
P\end{array}$}} & \multicolumn{2}{|c|}{84} & & \multicolumn{2}{|c|}{29.0} & \\
\hline & & \multicolumn{2}{|c|}{$<0.01$} & & \multicolumn{2}{|c|}{$<0.03$} & \\
\hline \multicolumn{2}{|c|}{ Mean $\%$ extr. } & & & 35.0 & & & 12.0 \\
\hline \multicolumn{2}{|c|}{ SEM } & & & 3.8 & & & 3.7 \\
\hline \multicolumn{2}{|c|}{$P \ddagger$} & & & $<0.01$ & & & $<0.01$ \\
\hline
\end{tabular}

Serial samples were taken at approximately 5-min intervals.

* $\%$ extr. $=100-[\mathrm{SVP} / \mathrm{A}] 100$.

$\ddagger$ Significance of the difference between the mean per cent extraction and zero.

Inspection of the serial arterial estrone concentrations for those dogs in which the MCR was calculated (Table II) indicates considerable variation in some instances. In the absence of significant regression such variation can be considered random and will include possible variation in the experimental system and variation due to the collection and analysis of samples. The coefficient of variation for all MCR values (expressed as liter/day per $\mathrm{m}^{2}$ ) was found to be 6.8 (Table $\mathrm{I}$ ). This compares with coefficients of variation for estrone MCR of 6.1 (males) and 5.3 (females) found in humans by Longcope, Layne, and Tait (22), 8.1 (males) and 3.6 (females) found by Hembree, Bardin, and Lipsett (24), and 7.4 and 8.0 for testosterone and $\Delta_{4}$-androstenedione MCR's in dogs found by Chapdelaine (25). Thus, the variation observed in the present study is in line with that found by other workers, and our MCR determinations appear valid insofar as they can be tested.

The mean plasma MCR for estrone in our series of male dogs can be compared with those reported for the male human. Mean plasma estrone MCR in nine males reported by Longcope et al. (22) was 1310 liters/day per $\mathrm{m}^{2}$ (SEM 80) and in five males by Hembree et al. (24) was 1168 liters/day per $\mathrm{m}^{2}$ (SEM 95). These mean values are substantially greater than those found in dogs in the present study (mean 731 liters/day per $\mathrm{m}^{2}$ ) presumably indicating a species difference. The mean plasma estrone MCR in the present series may also be compared with the estimated hepatic plasma flow (EHPF). The estimated hepatic blood flow (EHBF) in dogs lies in the range $23-44 \mathrm{ml} / \mathrm{min}$ per $\mathrm{kg}$ (26). Using an assumed mean hematocrit of $40 \%$, we get an EHPF of $14-26$ 
$\mathrm{ml} / \mathrm{min}$ per $\mathrm{kg}$. (Adjusting the EHBF figures for hematocrit is appropriate since the hematocrit has already been used for calculating the EHBF.) It will be seen that the values for MCR (mean $42.2 \mathrm{ml} / \mathrm{min}$ per $\mathrm{kg}$, SEM 2.9) are substantially greater than the values for EHPF. Since the mean splanchnic extraction of estrone has been shown in the present study (Table II) to be $85.9 \%$ (SEM 1.92), $45-71 \%$ of the total metabolism of estrone in dogs must therefore take place outside the splanchnic area. This in general agreement with the finding in human males where a minimum of $35 \%$ of the metabolism of estrone was calculated to be extrasplanchnic (22). (A minimal figure only can be given for the human since the splanchnic extraction of estrone in the human is as yet unknown.) In our dogs, red cells contained $<10 \%$ of total blood estrone- $6,7-{ }^{8} \mathrm{H}$, and this was true of both arterial and hepatic venous blood.

A steady state is also required in general if a comparison of simultaneous arterial and venous concentrations is to yield valid information of uptake or release of substances by tissues. This subject has been fully discussed by Zierler (27). Ideally tissue metabolism, blood flow, arterial, and venous concentrations should all remain constant during the period of observation. However, these parameters can seldom be measured independently, particularly in the case of tissue metabolism. The monitoring of blood flow is obviously desirable but was not considered practicable in the present study. Splanchnic blood flow estimations usually depend on hepatic extraction of dyes such as sulfobromophthalein (BSP). There is good evidence that estrogens depress the hepatic $\mathrm{T}_{\mathrm{m}}$ for BSP (28-30). Conversely it seemed likely that BSP administration would depress the hepatic extraction of estrogens. In the present study the volume of blood drawn was considered too small to have any significant effect; and since nothing else was done specifically to alter blood flow during arterial and venous sampling, any alterations in the splanchnic flow that may have occurred during the course of the experiments were assumed to be small and random.

As already stated the results of regression analysis of serial arterial and venous concentrations and of per cent extractions in Tables II-IV indicated no relationship to time in the majority of instances. In the few instances where significant regression in the arterial series did occur, it was possible to apply a correction. An arterial sample can be corrected for one transit time through the system before comparison with the simultaneously obtained venous sample (27). Although transit times through the splanchnic bed of the dog specifically for the various estrogens is not known, the transit time for blood has been measured and is in the range of $30-50 \mathrm{sec}(31)$. When this correction was applied, only trivial alterations in the observed $\mathrm{A}-\mathrm{V}$ differences resulted indicating that the transit time of the blood through the splanchnic bed is not a significant factor in interpretation of the $\mathrm{A}-\mathrm{V}$ differences obtained in the present study.

The variation to be observed in some of the arterial series has been mentioned above. This variation also extends to some of the venous and per cent extraction series (Tables II-IV). The sources of this variation have already been referred to and in the absence of regression in the vast majority of cases may be considered random. Such variation for all dogs in the appropriate categories is measured as SEMa or SEM (see Statistics). Where "significance" is obtained, the total variation must necessarily be small in relation to the effect (i.e., mean A-V difference, or difference between a mean per cent extraction and zero). Even though the variation in some individual dogs may be considerable, this clearly does not affect the validity of the analysis. Such variation is included in the estimate of total variation. Conclusions are based on the analysis of the results as a whole rather than on individual cases.

The values for the mean per cent extraction of estrone (85.9) and estradiol-17 $\beta$ (88.1) (Table II) indicate nearly complete extraction of these two estrogens in one passage through the splanchnic bed. A comparable per cent extraction has been found for aldosterone (32) in the human. The nearly complete extraction of estradiol-17 $\beta$ derived from estrone by the splanchnic bed is of interest, since it indicates no net formation of estradiol-17 $\beta$ by the splanchnic bed. This means either that the splanchnic bed forms no estradiol-17 $\beta$ from estrone for release into the systemic circulation or that estradiol-17 $\beta$ is formed to a very limited extent, in which case the extraction of that estradiol-17 $\beta$ which enters the splanchnic bed in arterial plasma would be even higher than the observed net extraction. This suggests in turn that the estrone $\rightleftarrows$ estradiol-17 $\beta$ interconversion may occur principally outside the splanchnic area. This is consistent with the previous calculation that a large proportion (45-71\%) of estrone metabolism is extrasplanchnic. Substantial extrasplanchnic metabolism of the similarly interconverting steroids testosterone and $\Delta_{4}$-androstenedione was observed in dogs by Chapdelaine (25).

The smaller but significant extraction of estrone sulfate (Table II) means that this conjugate is either excreted from the splanchnic bed, presumably into the bile (7), or further metabolized within the splanchnic bed.

In contrast, the negative A-HV per cent extraction of estrone glucosiduronate (Table II) indicates net production of this conjugate by the splanchnic bed. The size of the per cent extraction (-48.5\%) suggests that the splanchnic bed may be the major site of production of this metabolite. The negative per cent extraction of estradiol-17 $\beta$ glucosiduronate $(-33.3 \%$, Table II) like- 
wise indicates substantial production of this group of conjugates by the splanchnic bed.

The relationship (Table II) between the mean $A-V$ differences (ignoring sign) for estrone (2512 cpm, SEMd 399) and for estrone glucosiduronate (896 cpm, SEMd 213) on the one hand, and for estradiol-17 $\beta$ (388 cpm, SEM 49.3) and for estradiol-17 $\beta$ glucosiduronate (212 cpm, SEM 58.0) on the other, shows that the estrone glucosiduronate released from the splanchnic system into the systemic circulation is a significantly smaller proportion of estrone extracted by the splanchnic system than that in the case of estradiol-17 $\beta$ glucosiduronate and estradiol- $17 \beta$, respectively. This presumably indicates that estrone and estradiol-17 $\beta$ are metabolized somewhat differently by the splanchnic bed.

The separate activity of two major splanchnic organs, namely the small intestines and the spleen, can be estimated from the data in Tables III and IV. The data in Table III show that the intestine is highly active in the metabolism of blood-borne estrogens, as judged by the uptake of estrone and estradiol-17 $\beta$ and the release of estrone glucosiduronate. The mean per cent extraction of estrone (45.3, SEM 2.60) and of estradiol-17 $\beta$ (46.1, SEM 12.9) were similar. Both were considerably lower than the corresponding extraction of the splanchnic bed as a whole. This indicates that further extraction, of both substances takes place at some other site within the splanchnic bed. Since the per cent extraction due to the spleen (Table IV) is approximately the same as for the small intestine and since the large intestine is thought to be inactive in estrogen metabolism (35), the probable site of further estrone and estradiol-17 $\beta$ extraction is the liver.

The mean per cent extraction (-30.8, SEM 7.9) for estrone glucosiduronate indicates substantial net production of estrone glucosiduronate by the intestines. The intestines must therefore be a principal site for the formation of estrone glucosiduronate from blood-borne estrone within the splanchnic system. Failure to show significant A-SMV differences for estrone sulfate and estradiol-17 $\beta$ glucosiduronate suggests that large quantities of these substances are not taken up or released by the intestine.

In the interpretation of the A-SMV differences, the excretory and absorptive properties of the intestines have to be taken into account, together with the possible effects of the enterohepatic circulation of estrogens previously referred to. The significant uptake of bloodborne estrone and estradiol-17 $\beta$ could represent excretion into the intestinal lumen rather than metabolism in the intestinal wall. Equally the significant release of estrone glucosiduronate into the superior mesenteric vein could be due to absorption of this substance (or of a precursor) brought to the intestinal lumen via the bile. However, it is unlikely that these two separate processes are involved. The experiments were designed to be short-term specifically in order to exclude effects due to the enterohepatic circulation. The duration of the experiments $(30-45 \mathrm{~min})$ would hardly allow enough time for the formation of conjugates, transfer into the bile, transport to the intestinal lumen, further metabolism, and transfer into the superior mesenteric vein. This process is thought to take about $6 \mathrm{hr}$ in the human $(1,2)$. A single explanation is both simpler and more obvious, namely, that arterial plasma estrone and estradiol- $17 \boldsymbol{\beta}$ are taken up by the intestine and metabolized, resulting in the formation of estrone glucosiduronate by intestinal tistsue. The intestinal wall is known to have the capacity to conjugate estrogens with glucuronic acid, but this has so far been shown only for estrogens introduced into the intestinal lumen $(6,11$, 33-38).

A different pattern in estrogen metabolism is seen in the spleen (Table IV). There was again uptake of estrone (mean per cent extraction 35.0, SEM 38) which was of the same order as that by the intestine, but less than that of the splanchnic bed as whole. However, in contrast to the intestines and the splanchnic bed as a whole, there was a small but significant uptake of estrone glucosiduronate (mean extraction 12\%, SEM 3.7). Since excretion is not possible, the most likely explanation is that the spleen metabolizes small quantities of estrone glucosiduronate by hydrolysis. This organ is known to contain substantial amounts of $\beta$-glucuronidase activity in various animal species (39).

The splanchnic metabolism of blood-borne estrogens in the dog is complex in terms of the number of the major splanchnic organs involved and in the different patterns of activity exhibited. The contribution of each organ to over-all splanchnic metabolism must depend upon relative blood flow through that organ, as well as on the $\mathrm{A}-\mathrm{V}$ difference. Venous drainage from the intestine accounts for about $60 \%$ of the blood flow through the portal vein in the dog and is approximately $12 \%$ of the cardiac output (40). These figures taken with the values for uptake of arterial estrone and estradiol-17 $\beta$ and release of estrone glucosiduronate gives some indication of the quantitative potential of the intestine in estrogen metabolism. Venous drainage from the spleen accounts for only about $10 \%$ of the portal venous flow and is approximately $2 \%$ of the cardiac output (40). Nevertheless, the demonstration of uptake of estrone and of estrone glucosiduronate indicates that the spleen plays some role in splanchnic estrogen metabolism, which could assume importance in certain circumstances. It seems possible that in those forms of human liver disease where liver function is insufficient and the enterohepatic circulation of estrogens is impaired, but 
where collateral venous circulation allows adequate venous drainage from the intestine and spleen (e.g., in hepatic cirrhosis), the intestine, with the spleen, could take over the greater part of splanchnic estrogen metabolism.

\section{ACKNOWLEDGMENTS}

We gratefully acknowledge the invaluable assistance of the following doctors whose surgical skills as medical students made these experiments possible: Richard M. Boozer, William P. Potsic, Burton V. Reifler, Lucian C. Rice, Julian McK. Whitaker, and William G. Whitaker.

This investigation was supported by U. S. Public Health Service Research Grants 5-RO1-AM02221 and 5-RO1AM13468.

\section{REFERENCES}

1. Adlercreutz, H. 1962. Studies on oestrogen excretion in human bile. Acta Endocrinol. Suppl. 72.

2. Adlercreutz, H., and T. Luukkainen. 1967. Biochemcial and clinical aspects of the enterohepatic circulation of oestrogens. Acta Endocrinol. Suppl. 124.

3. Emerman, S., G. H. Twombly, and M. Levitz. 1967. Biliary and urinary metabolites of estriol-15- ${ }^{3} \mathrm{H}$-sulfate ${ }^{35} \mathrm{~S}$ in women. J. Clin. Endocrinol. Metab. 27: 539.

4. Jirku, H., V. Hogsander, and M. Levitz. 1967. 15 $\alpha-$ hydroxyestrone "sulfate." A biliary metabolite of estrone sulfate in the non-pregnant female. Biochim. Biophy's. Acta. 137: 588 .

5. Levitz, M., and J. Katz. 1968. Enterohepatic metabolism of estriol-3-conjugate-16-glucosiduronate in women. $J$. Clin. Endocrinol. Metab. 28: 862.

6. Stoa, K. F., and M. Levitz. 1968. Comparison of the conjugated metabolites of intravenously and intraduodenally administered oestriol. Acta Endocrinol. 57: 657.

7. Jirku, H., and M. Levitz. 1969. Biliary and urinary metabolites of estrone- $6,7-{ }^{3} \mathrm{H}$-sulfate $-{ }^{35} \mathrm{~S}$ in a woman. $J$. Clin. Endocrinol. Metab. 29: 615.

8. Sandberg, A. A., and W. R. Slaunwhite, Jr. 1965. Studies on phenolic steroids in human subjects. VII. Metabolic fate of estriol and its glucuronide. J. Clin. Invest. 44: 694 .

9. Sandberg, A. A., and W. R. Slaunwhite, Jr. 1957. Studies on phenolic steroids in human subjects. II. Metabolic fate and hepatic-biliary-enteric circulation of ${ }^{14} \mathrm{C}$ estrone and ${ }^{14} \mathrm{C}$ estradiol in women. J. Clin. Invest. 36: 1266.

10. Inove, N., A. A. Sandberg, J. B. Graham, and W. R. Slaunwhite, Jr. 1969. Studies on phenolic steroids in human subjects. VII. Metabolism of estriol-16 $\alpha$-glucosiduronate. J. Clin. Invest. 48: 380.

11. Inove, N., A. A. Sandberg, J. B. Graham, and W. R. Slaunwhite, Jr. 1969. Studies on phenolic steroids in human subjects. IX. The role of the intestine in the conjugation of estriol. J. Clin. Invest. 48: 390.

12. Kirdani, R. Y., W. R. Slaunwhite, Jr., and A. A. Sandberg. 1969. Studies in phenolic steroids in human subjects. X. Metabolic fate of estriol-3,16-diglucosiduronate. Steroids. 13: 257.

13. Balikian, H., J. Southerland, C. M. Howard, and J. R. K. Preedy. 1968. Estrogen metabolism in the male dog. Uptake and disappearance of specific radioactive estrogens in tissues and plasma following estrone- $6,7-{ }^{3} \mathrm{H}$ administration. Identification of estriol $-16 \alpha, 17 \alpha$ in tissues and urine. Endocrinology. 82: 500 .

14. Cantarow, A., A. E. Rakoff, K. E. Paschkis, L. P. Hansen, and A. A. Walkling. 1942. Excretion of estrogen in bile. Endocrinology. 31: 515.

15. Gilmore, J. P. 1958. Effect of anasthesia and hepatic sampling site upon hepatic blood flow. Amer. J. Physiol. 195: 465 .

16. Fisher, B., C. Ross, R. G. Selker, and E. J. Fedor. 1956. Observations on liver blood flow: its relationship to cardiac output in anasthetised and unanesthetised animals. Amer. Med. Ass. Arch. Surg. 72: 600.

17. Crowell, G. C., M. E. Turner, Jr., F. H. Schmidt, C. M. Howard, and J. R. K. Preedy. 1967. Estrogen metabolism in the human. I. Studies in the male using estrone$6,7-{ }^{8} \mathrm{H}$ with special reference to estrone production rate determinations, the origin of certain urinary estrogen conjugates and the use of a new mathematical model. J. Clin. Endocrinol. Metab. 27: 807.

18. Elce, J. S., J. G. D. Carpenter, and A. E. Kellie. 1967. The synthesis of oestrogen monoglucuronides. J. Chem. Soc. (London). $7: 542$.

19. Preedy, J. R. K., and E. H. Aitken. 1961. The determination of estrone, estradiol-17 $\beta$ and estriol in urine and plasma with column partition chromatography. $J$. Biol. Chem. 236: 1300.

20. Wusterman, F. S., K. S. Dodgson, A. C. Lloyd, E. A. Rose, and N. J. Tudball. 1964. Thin layer chromatography in the study of ester sulfates. J. Chromatogr. 16: 334

21. Hobkirk, R., P. Musey, and M. Nilsen. 1969. Chromatographic separation of estrone and $17 \beta$-estradiol conjugates on DEAE-sephadex. Steroids. 14: 191.

22. Longcope, C., D. S. Layne, and J. F. Tait. 1968. Metabolic clearance rates and interconversions of estrone and $17 \beta$-estradiol in normal males and females. J. Clin. Invest. $47: 93$.

23. DuBois, E. F. 1936. Basal Metabolism in Health and Disease. Lea and Febiger, Philadelphia. 142.

24. Hembree, W. C., C. W. Bardin, and M. B. Lipsett. 1969. A study of estrogen metabolic clearance rates and transfer factors. J. Clin. Invest. 48: 1809.

25. Chapdelaine, A. 1969. Sites of in vivo extraction and interconversion of testosterone and androstenedione in dogs. J. Clin. Invest. 48: 2063.

26. Fischer, A. 1963. Dynamics of the circulation in the liver. In The Liver: Morphology, Biochemistry, Physiology. Ch. Rouiller, editor. Academic Press, Inc., New York. Chap. 7. 1: 335.

27. Zierler, K. L. 1961. Theory of the use of arterio-venous concentration differences for measuring metabolism in steady and non-steady states. J. Clin. Invest. 36: 2111.

28. Combes, B., H. Shibata, R. Adams, B. Mitchell, and V. Trammell. 1963. Alterations in sulfobromophthalein sodium removal mechanisms from blood during normal pregnancy. J. Clin. Invest. 42: 1431.

29. Mueller, M. N., and A. Kappas. 1964. Estrogen pharmacology. I. The influence of estradiol and estriol in hepatic disposal of sulfobromophthalein (BSP) in man. J. Clin. Invest. 43: 1905.

30. Kottra, L. L., and A. Kappas. 1966. Estrogen pharmacology. III. Effect of estradiol on plasma disappearance rate of sulfobromophthalein in man. Arch. Intern. Med. $117: 373$. 
31. Wheeler, H. O., B. Combes, A. W. Childs, and O. L. Wade. 1955. The splanchnic circulation time. Trans. Ass. Amer. Physicians Philadelphia. 68: 177.

32. Tait, J. F., J. Bougas, B. Little, S. A. S. Tait, and C. Flood. 1965. Splanchnic extraction and clearance of aldosterone in subjects with minimal and marked cardiac dysfunction. J. Clin. Invest. 25: 219.

33. Dizcfalusy, E., C. Franksson, B. P. Lisboa, and B. Martinsen. 1963. Formation of oestrone glucosiduronate by the human intestinal tract. Acta Endocrinol. 40: 537.

34. Meli, A., D. I. Cargill, T. Giannina, and B. G. Steinetz. 1968. Studies on the transport of estrogens by the rat small intestine in vivo. Proc. Soc. Exp. Biol. Med. 129: 937.

35. Diczfalusy, E., C. Franksson, and B. Martinsen. 1961. Oestrogen conjugation by the human intestinal tract. Acta Endocrinol. 38: 59.
36. Lisboa, B. P., I. Drosse, and H. Breuer. 1965. Resorption, Stoffwechsel und Transport von Östradiol- $(17 \beta)$ und Ǒstradiol-(17 $\beta$ )-3-Monosulfat im Dünndarm der Ratte. Hoppe-Seyler's Z. Physiol. Chem. 342: 106.

37. Fishman, J., S. Goldberg, R. S. Rosenfeld, B. Zumoff, L. Hellman, and T. F. Gallagher. 1969. Intermediates in the transformation of oral estradiol. J. Clin. Endocrinol. Metab. 29: 41.

38. Dahm, K., and H. Breuer. 1966. Biogenese von Ostriol$16 \alpha$-Monoglucuronid und Ostriol-17 $\beta$-Monoglucuronid. Acta Endocrinol. 52: 43.

39. Whittemore, K. S., and D. S. Layne. 1965. Hydrolysis of two $17 \alpha$-Oestradiol glycosides by rabbit tissue glucosidases. Nature (London). 208: 288.

40. Grim, E. 1963. The flow of blood in the mesenteric vessels. In Handbook of Physiology. W. F. Hamilton and P. Dow, editors. American Physiological Society, Washington, D. C. Sect. 2. Chap. 42. 2: 1443. 